\title{
TU/e EmonOWEN

\section{Influence of the assembly state on the functionality of a supramolecular jagged1-mimicking peptide additive}

\section{Citation for published version (APA):}

Putti, M., Stassen, O. M. J. A., Schotman, M. J. G., Sahlgren, C. M., \& Dankers, P. Y. W. (2019). Influence of the assembly state on the functionality of a supramolecular jagged1-mimicking peptide additive. ACS Omega, 4(5), 8178-8187. https://doi.org/10.1021/acsomega.9b00869

DOI:

10.1021/acsomega.9b00869

Document status and date:

Published: 03/05/2019

\section{Document Version:}

Publisher's PDF, also known as Version of Record (includes final page, issue and volume numbers)

\section{Please check the document version of this publication:}

- A submitted manuscript is the version of the article upon submission and before peer-review. There can be important differences between the submitted version and the official published version of record. People interested in the research are advised to contact the author for the final version of the publication, or visit the $\mathrm{DOI}$ to the publisher's website.

- The final author version and the galley proof are versions of the publication after peer review.

- The final published version features the final layout of the paper including the volume, issue and page numbers.

Link to publication

\section{General rights}

Copyright and moral rights for the publications made accessible in the public portal are retained by the authors and/or other copyright owners and it is a condition of accessing publications that users recognise and abide by the legal requirements associated with these rights.

- Users may download and print one copy of any publication from the public portal for the purpose of private study or research.

- You may not further distribute the material or use it for any profit-making activity or commercial gain

- You may freely distribute the URL identifying the publication in the public portal.

If the publication is distributed under the terms of Article 25fa of the Dutch Copyright Act, indicated by the "Taverne" license above, please follow below link for the End User Agreement:

www.tue.nl/taverne

Take down policy

If you believe that this document breaches copyright please contact us at:

openaccess@tue.nl

providing details and we will investigate your claim. 


\title{
Influence of the Assembly State on the Functionality of a Supramolecular Jagged1-Mimicking Peptide Additive
}

\author{
Matilde Putti, ${ }^{\dagger, \ddagger}$, Oscar M. J. A. Stassen, ${ }^{\S}$ Maaike J. G. Schotman, ${ }^{\dagger, \dagger}$ Cecilia M. Sahlgren, ${ }^{\dagger, \S, \|, \perp}$ \\ and Patricia Y. W. Dankers $*, \dagger, \$,{ }_{0}$ \\ ${ }_{\dagger}^{\dagger}$ Institute for Complex Molecular Systems, ${ }^{\ddagger}$ Laboratory for Chemical Biology, and ${ }^{\S}$ Laboratory for Cell and Tissue Engineering, \\ Eindhoven University of Technology, Eindhoven 5612 AZ, The Netherlands \\ "Faculty for Science and Engineering, Biosciences, Åbo Akademi University, Turku 20500, Finland \\ ${ }^{\perp}$ Turku Centre for Biotechnology, University of Turku and Åbo Akademi University, Turku 20500, Finland
}

\section{Supporting Information}

\begin{abstract}
Expanding the bioactivation toolbox of supramolecular materials is of utmost relevance for their broad applicability in regenerative medicines. This study explores the functionality of a peptide mimic of the Notch ligand Jagged 1 in a supramolecular system that is based on hydrogen bonding ureido-pyrimidinone (UPy) units. The functionality of the peptide is studied when formulated as an additive in a supramolecular solid material and as a self-assembled system in solution. UPy conjugation of the DSL $\mathrm{JAG}_{\mathrm{JA} 1}$ peptide sequence allows for the supramolecular functionalization of UPymodified polycaprolactone, an elastomeric material, with UPy-DSL $\mathrm{JAG}_{\mathrm{JA} 1}$. Surface presentation of the UPy-DSL $\mathrm{JAG}_{\mathrm{JA}}$ peptide was confirmed by atomic force microscopy and X-ray photoelectron spectroscopy analyses, but no enhancement of Notch activity was detected in cells presenting Notch1 and Notch3 receptors. Nevertheless, a significant increase in Notch-signaling activity was observed when DSL $_{\text {JAG1 }}$ peptides were administered in the soluble form, indicating that the activity of DSL $\mathrm{JAG}_{\mathrm{A} 1}$ is preserved after UPy functionalization but not after immobilization on a supramolecular solid material. Interestingly, an enhanced activity in solution of the UPy conjugate was detected compared with the unconjugated $\mathrm{DSL}_{\mathrm{JAG}}$ peptide, suggesting that the self-assembly of supramolecular aggregates in solution ameliorates the functionality of the molecules in a biological context.
\end{abstract}

\section{INTRODUCTION}

The Notch-signaling pathway is a cell-cell communication pathway that regulates a variety of vital functions such as cell fate decisions and terminal differentiation. It also contributes to development and homeostasis of several tissues and organs. ${ }^{1,2}$ Particularly relevant to in situ approaches in tissue engineering is the notion that organism's regenerative potential is related to the behavior and self-renewal of stem cells, which is controlled by Notch ligand-receptor engagement and the interaction of Notch signaling with the surrounding extracellular matrix (ECM) components. ${ }^{3-5}$ The role of Jagged 1 has been emphasized in the renovation of stem cell populations, ${ }^{6,7}$ for which artificial niches for stem cells have been created by integrating an active fragment on ECM-mimicking substrates. ${ }^{8}$ Furthermore, Jagged1-mediated Notch signaling is shown to accelerate vascular repair when specifically overexpressed in the endothelium ${ }^{9}$ and is also involved in contrasting aging-related loss of regenerative potential. Kusumbe et al. reported the revival of vascular niches when endothelial Notch activity was restored in the aging organism, thereby highlighting the pivotal role of the Notch pathway in tissue restoration. ${ }^{10}$ With these premises, we hypothesized that a material capable of enhancing
Notch-signaling activity has outstanding potential to improve the outcome of regenerative therapies, with special emphasis on those targeting the cardiovascular system.

A 17 amino acid-long peptide $\left(\mathrm{DSL}_{\mathrm{JAG1}}\right)$ capable of engaging the Notch1 receptor was identified by $\mathrm{Li}$ et al. ${ }^{11}$ It corresponds to residues 188-204 of the Jagged1 ligand's Delta/Serrate/Lag2 (DSL) region and showed Notch1 agonist activity. ${ }^{12}$ Polymers functionalized via this Jagged1's DSLderived peptide have been created through covalent modification of alginate and modulated stem cell behavior. ${ }^{13}$ A self-assembling hydrogel system developed by Boopathy et al. ${ }^{14}$ was also functionalized with the Jagged1-mimicking peptide and was injected in combination with cardiomyocyte progenitor cells in a rat myocardial infarction model. It was shown to significantly improve cardiac function and reduce fibrosis compared to the pristine gel or the gel containing the scrambled peptide sequence. ${ }^{15}$ Conversely, Beckstead et al. ${ }^{16}$ observed no activation of the Notch/CSL pathway when

Received: April 3, 2019

Accepted: April 18, 2019

Published: May 3, 2019 
A)

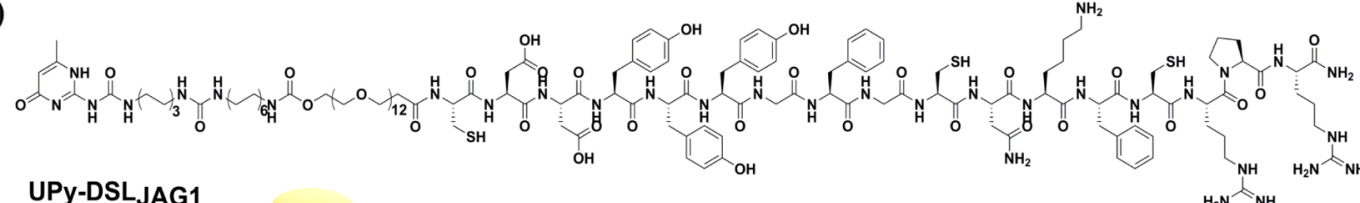

UPy-DSLJAG1

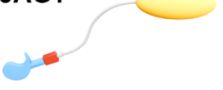

B) + UPy-PCL: solid material functionalization

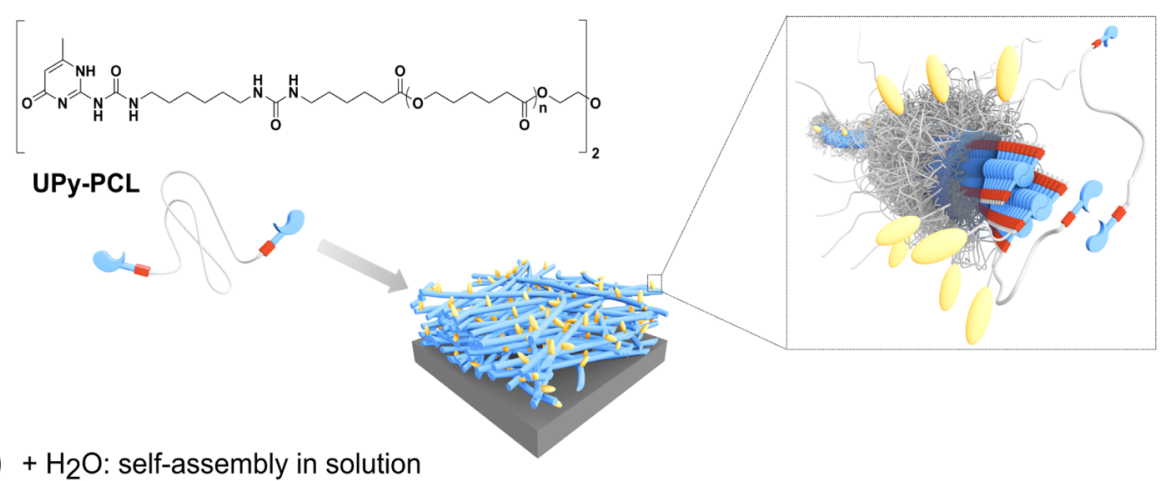

C) $+\mathrm{H}_{2} \mathrm{O}$ : self-assembly in solution

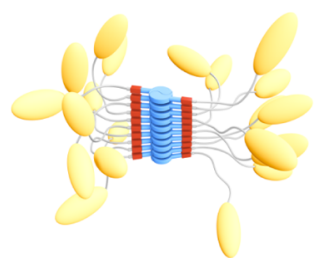

Figure 1. Chemical structures of compounds used in this study and schematic representations of the supramolecular platforms and their components: UPy unit (blue), urea-alkyl spacer (red), oligo(ethylene glycol) spacer (white), and peptide sequence (yellow). (A) Chemical structure of UPy-DSL $\mathrm{JAG1}_{\mathrm{J} 1}$ (B) Solid material functionalization by mixing UPy-DSL $\mathrm{JAG}_{1}$ with UPy-PCL, with detailed zoom of the co-assembly of the two components in the solid state. (C) Supramolecular fibrous stack formed in solution by UPy-DSL JAG1 $_{1}$.

seeding primary human keratinocytes on poly(2-hydrohyethyl methacrylate) surfaces functionalized with the same Jagged1mimicking peptide.

Most of the reported biomaterials containing the Jagged1mimicking peptides are based on hydrogels, while elastomeric, solid materials might be more preferable for load-bearing in situ tissue engineering applications in terms of mechanical properties. At the best of our knowledge, the only example of a biodegradable elastomeric material modified with $\mathrm{DSL}_{\mathrm{JAG} 1}$ is achieved by applying conventional carbodiimide-N-hydroxysuccinimide (NHS) chemistry to graft the peptide to a poly(acrylic acid) brush grown on a substrate of poly(L-lactideco-caprolactone). In this study by Wen et al., activation of the Notch-signaling pathway induced differentiation of mesenchymal stem cells toward the myogenic lineage. ${ }^{17}$

Supramolecular biomaterials based on the four-fold hydrogen bonding ureido-pyrimidinone (UPy) moiety have been developed and investigated for several biomedical applications because of their biocompatibility, modular properties, and scalable production. ${ }^{18,19}$

In water, dimerized UPy units form stacks by binding laterally via $\pi-\pi$ and hydrophobic interactions. The hydrogenbonded stacks are shielded from the polar environment by hydrophobic alkyl chains and water-stable oligo(ethylene glycol), thereby being stabilized and allowed to form fibrous aggregates. $^{20-22}$ This resulted in the development of UPy particles that can be delivered inside cells. ${ }^{21}$ Furthermore, similar water-soluble UPy compounds were designed to make supramolecular transient networks and hydrogels that were applied for the delivery of various drugs to the heart and kidney. $^{20,23}$

With the aim to enlarge the application prospects of this class of biomedical materials, modular building blocks modified with UPy groups have been employed to introduce bioactivity in several solid materials to be used for tissue engineering and regenerative medicine. Elastomeric, solid materials based on the UPy owe their dynamic nature to the reversibility of the supramolecular interactions present in the system. Both UPy motifs and flanking urea units contribute to the supramolecular interactions, leading to a nanofibrous morphology of the material. ${ }^{24}$ Robust incorporation of UPyfunctionalized bioactives in solid material systems is achieved through intercalation inside the fibers of matching supramolecular moieties and linkers used to functionalize the additive. ${ }^{25}$ Various UPy-functionalized compounds have been developed to be applied as bioactive additives to generate supramolecular elastomeric materials with improved cell adhesive (RGD, YIGSR), ${ }^{26}$ nonfouling (oligo(ethylene glycol)), ${ }^{27}$ heparin-binding (GLRKKLGKA), ${ }^{28}$ and antimicrobial $^{29}$ and cell-attracting (SDF- $1 \alpha$ mimicking SKPVSLSYR) $)^{30}$ properties. Here, for the first time, we target intercellular signaling processes by means of a UPy-modified Jagged1mimicking peptide (UPy-DSL $\mathrm{JAG1}_{\mathrm{J} 1}$ ) introduced into supramolecular systems. To achieve solid material functionalization, 
UPy-DSL $_{\text {JAG1 }}$ (Figure 1A) was mixed into UPy-modified polycaprolactone (UPy-PCL) (Figure 1B) and surface analyses were carried out on cast films to confirm surface exposure of the additive. Supramolecular aggregates were formed in aqueous solution (Figure 1C) and visualized by electron microscopy. Subsequently, measurements of Notch-signaling activity in different cell models revealed the role of the assembly state in the functionality of UPy-DSL $\mathrm{JAG1}_{1}$.

\section{EXPERIMENTAL SECTION}

2.1. Materials and Synthetic Procedures. Telechellically UPy-PCL $\left(M_{\mathrm{n}}=2.7 \mathrm{~kg} / \mathrm{mol}\right)$ was synthesized according to previously described methods. ${ }^{31}$ Synthesis of Jagged1mimicking peptide (DSL ${ }_{\mathrm{JAG} 1}, \mathrm{MW}=2106.4 \mathrm{~g} / \mathrm{mol}$ ) was carried out on the solid phase using standard Fmoc-chemistry to synthesize the sequence CDDYYYGFGCNKFCRPR. Amino acids were activated with $\mathrm{O}-(1 \mathrm{H}-6$-chlorobenzotriazole-1-yl)-1,1,3,3-tetramethyluronium hexafluorophosphate in the presence of $N, N$-diisopropylethylamine (DIPEA) for 10 min before the coupling reaction. Conjugation of UPycarboxylic acid ( $\mathrm{UPy}-\mathrm{COOH}, \mathrm{MW}=1138.4 \mathrm{~g} / \mathrm{mol}$ ) to the $\mathrm{N}$-terminus of $\mathrm{DSL}_{\mathrm{JAG} 1}$ was performed on the solid phase via an amide formation strategy to obtain UPy-Jagged 1 mimicking peptide (UPy-DSL ${ }_{\mathrm{JAG} 1}, \mathrm{MW}=3226.8 \mathrm{~g} / \mathrm{mol}$ ). The UPycarboxylic acid synthon was activated with 1-[bis(dimethylamino) methylene]-1H-1,2,3-triazolo[4,5-b]pyridinium 3-oxid hexafluorophosphate (HATU) in the presence of DIPEA for $30 \mathrm{~min}$ before the coupling reaction. The products were purified with prep-RP-HPLC using gradients of acetonitrile in water (with $0.1 \mathrm{vol} \%$ trifluoroacetic acid) and the collected fractions were freeze-dried and analysed by reversed phase high-performance liquid chromatography-mass spectrometry (RP-HPLC-MS) to confirm the purity. Detailed synthetic procedures and purifications and general materials and instrumentations are described in the Supporting Information.

2.2. Preparation of Drop Cast Surfaces. For preparation of UPy-PCL films, the UPy-PCL polymer was dissolved in 1,1,1,3,3,3-hexafluoroisopropanol (HFIP) at a concentration of $25 \mathrm{mg} / \mathrm{mL}$. For preparation of UPy-DSL $\mathrm{JAG}_{\mathrm{J} 1}$, functionalized surfaces, 1 and $5 \mathrm{~mol} \%$ of UPy-DSL $\mathrm{JAG}_{\mathrm{J} 1}$, were mixed to UPyPCL from stock solutions in HFIP. Drop-cast films were prepared by distributing $50 \mu \mathrm{L}$ of solution on a $13 \mathrm{~mm} \varnothing$ glass coverslip. The HFIP was evaporated overnight in vacuo at 40 ${ }^{\circ} \mathrm{C}$.

2.3. Material Characterization. 2.3.1. Atomic Force Microscopy. The atomic force microscopy (AFM) phase and height images of drop-cast films were recorded at room temperature using Digital Instruments MultiMode NanoScope IV operating in the tapping regime mode using silicon cantilever tips (PPP-NCHR, 204-497 kHz, 10-130 N/m). Images were processed using Gwyddion software (version 2.43).

2.3.2. Water Contact Angle Measurements. Water contact angle (WCA) measurements on drop-cast films were performed on an OCA 30 system from Dataphysics using SCA20 software. A $5 \mu \mathrm{L}$ drop of deionized water was placed in three different regions of three different samples. Images were captured $10 \mathrm{~s}$ after placement of the water drop. WCAs were determined from the recorded images.

2.3.3. X-ray Photoelectron Spectroscopy. X-ray photoelectron spectroscopy (XPS) was performed on drop-cast films prepared as described, and spectra were recorded using a
Thermo Scientific K-Alpha spectrometer equipped with a monochromatic, small-spot X-ray source and a $180^{\circ}$ double focusing hemispherical analyzer with a 128-channel detector. Spectra were obtained using an aluminum anode ( $\mathrm{Al} \mathrm{K} \alpha$, $1486.6 \mathrm{eV}$ ) operating at $72 \mathrm{~W}$. Survey scans were measured at a pass energy of $200 \mathrm{eV}$ and region scans at a pass energy of 50 $\mathrm{eV}$. Analysis and quantification of the spectra were performed using the CasaXPS software version 2.3.16, using the $\mathrm{C} 1 \mathrm{~s}, \mathrm{~N}$ $1 \mathrm{~s}, \mathrm{O} 1 \mathrm{~s}$, and $\mathrm{S} 1 \mathrm{~s}$ regions.

2.3.4. Cryogenic Transmission Electron Microscopy. For cryogenic transmission electron microscopy (cryo-TEM), vitrified films were prepared in a "Vitrobot' instrument at 22 ${ }^{\circ} \mathrm{C}$ and at a relative humidity of $100 \%$. In the preparation chamber of the "Vitrobot", a $3 \mu \mathrm{L}$ sample was applied on a Quantifoil grid (R 2/2, Quantifoil Micro Tools GmbH), which was surface plasma-treated just prior to use (Cressington 208 carbon coater operating at $5 \mathrm{~mA}$ for $40 \mathrm{~s}$ ). Excess sample was removed by blotting using filter paper for $3 \mathrm{~s}$ at $-3 \mathrm{~mm}$, and the thin film thus formed was plunged into liquid ethane just above its freezing point. The vitrified film was transferred to a cryoholder (Gatan 626) and observed at temperatures below $-170{ }^{\circ} \mathrm{C}$ in FEI Titan TEM equipped with a field emission gun and operating at $300 \mathrm{kV}$. Micrographs were taken at low dose conditions, using a defocus setting of $10 \mu \mathrm{m}$ at 25000 magnification (detail pictures), or a defocus setting of $20 \mu \mathrm{m}$ at 6500 magnification (overview pictures).

2.3.5. Nile Red Encapsulation Assay. Molecules were dissolved in Milli-Q water at $50 \mu \mathrm{M}$ concentrations and the aggregates were allowed to form on a shaking plate overnight. Nile Red was added to the solution to a final concentration of $5 \mu \mathrm{M}$ and samples were equilibrated for $5 \mathrm{~min}$. Nile Red was excited at $550 \mathrm{~nm}$ and the emission intensity was recorded from 565 to $700 \mathrm{~nm}$. Fluorescence data were recorded on a Varian Cary Eclipse fluorescence spectrometer using Quartz cuvettes, and five scans were collected and averaged.

2.4. Cell Experiments. 2.4.1. Cell Culture. Human embryonic kidney (HEK) 293T cells stably expressing fulllength Notch1 (HEK293 FLN1) were cultured under puromycin selection $(1 \mu \mathrm{g} / \mathrm{mL})$ in complete medium consisting of Dulbecco's modified Eagle medium (Gibco) supplemented with 5 vol \% heat inactivated fetal bovine serum (Invitrogen) and 1 vol \% penicillin-streptomycin solution (Invitrogen), at $37{ }^{\circ} \mathrm{C}$ and $5 \% \mathrm{CO}_{2}$ in a humidified atmosphere. HEK293 FLN1 were seeded at a concentration of $1.0 \times 10^{5}$ cells $/ \mathrm{cm}^{2}$.

Primary human coronary artery smooth muscle cells (HCASMC, Lonza) were purchased at passage 3 and experiments were carried out with cells at passage 5 or 6 . Cells were cultured in 231 basal medium (Gibco) supplemented with 5 vol \% smooth muscle growth supplement (SMGS, Gibco) and 1 vol \% penicillin-streptomycin solution (Invitrogen), at $37{ }^{\circ} \mathrm{C}$ and $5 \% \mathrm{CO}_{2}$ in a humidified incubator. As a control for the expression of $\alpha$-smooth muscle actin in the differentiated state, the basal medium was supplemented with 1 vol \% smooth muscle differentiation supplement (Gibco) instead of SMGS. HCASMC was passaged at $80 \%$ confluency and seeded at a concentration of $5 \times 10^{3}$ cells $/ \mathrm{cm}^{2}$.

2.4.2. Activation of Notch Signaling by Immobilized Ligands. For induction of Notch signaling with the immobilized Jagged1 ligand, cell culture plates were coated overnight with recombinant protein G (Thermo Fisher) 50 $\mu \mathrm{g} / \mathrm{mL}$ in phosphate buffered saline (PBS). After coating, plates were washed three times with PBS and further blocked 
A) $\mathrm{UPy}-\mathrm{PCL}$

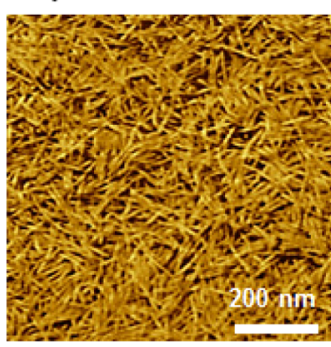

B)

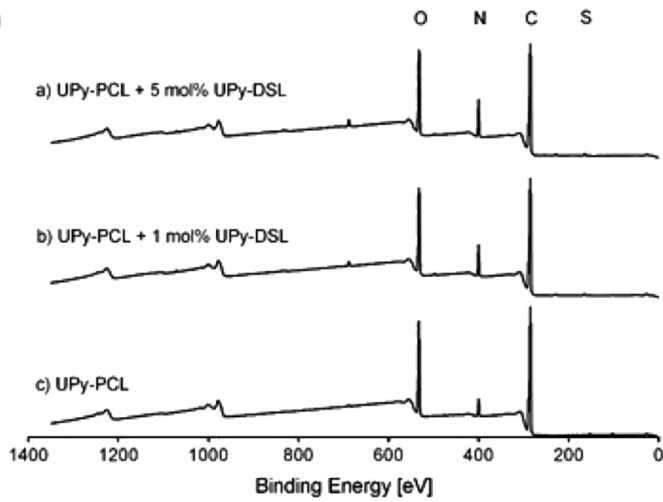

$+1 \mathrm{~mol} \%$ UPy-DSL

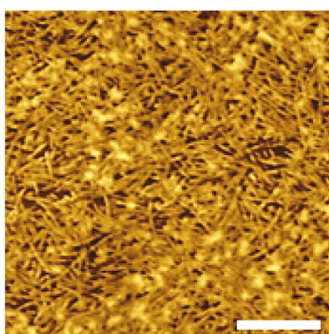

C)
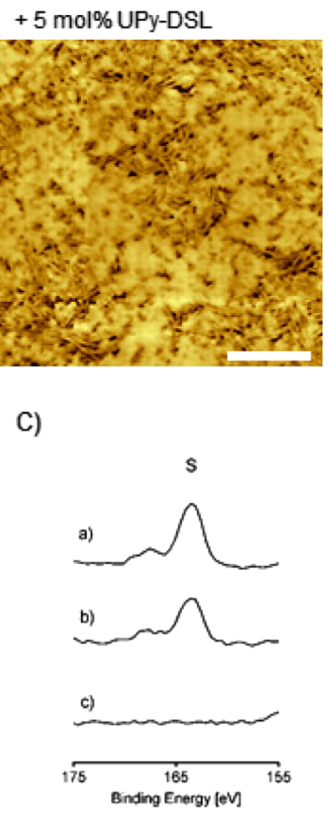

Figure 2. Surface characterization of drop-cast samples of UPy-PCL with the addition of UPy-DSL concentration of 1 and 5 mol \% and HEK293 FLN1 cell response. (A) AFM micrographs in the phase mode. (B) XPS spectra with highlighted peaks corresponding to elements of interest. (C) Magnification of the XPS spectrum at the characteristic binding energy interval of $S 1 \mathrm{~s}$ for the different material compositions.

with bovine serum albumin (BSA, $10 \mathrm{mg} / \mathrm{mL}$ ) in PBS for $2 \mathrm{~h}$. The blocked plates were washed three times with PBS and incubated with recombinant Jagged1-Fc chimera (R\&D systems) or only immunoglobulin G Fc fragment (Jackson ImmunoResearch) at concentrations of $1 \mu \mathrm{g} / \mathrm{mL}$ in BSA 1 $\mathrm{mg} / \mathrm{mL}$ in PBS for $3 \mathrm{~h}$. After washing $3 \times$ with PBS, cells were immediately seeded on the coated plates. ${ }^{32}$

The activity of soluble $\mathrm{DSL}_{\mathrm{JAG} 1}$ and UPy-DSL $\mathrm{JAG}_{\mathrm{J} 1}$ was investigated by the addition of 10,50 , and $100 \mu \mathrm{M}$ compounds to the culture medium from stock solutions in dimethylsulphoxide (DMSO). Inhibition was performed by the addition of $10 \mu \mathrm{M} N$-[N-(3,5-difluorophenacetyl)-L-alanyl $]-S$-phenylglycine $t$-butyl ester (DAPT, Sigma-Aldrich) to the culture medium from stock solutions in DMSO (Sigma-Aldrich). For vehicle control, all other groups were treated with the same amount of DMSO.

2.4.3. Reporter Assay. HEK293 FLN1 cells were transfected with a previously described $12 \times$ CSL-luciferase reporter construct $^{33}$ (250 ng per $10^{5}$ cells) directly in the culture flask one day before seeding. Poly(ethylene imine) (SigmaAldrich) was used as a transfection vector in the 2:1 ratio with the DNA construct. Luminescence intensity was detected after $48 \mathrm{~h}$ from seeding with a Luciferase Assay Kit (Promega) following manufacturer's instruction $(n \geq 6)$.

2.4.4. Gene Expression Analyses. For gene expression analysis, HCASMC was cultured on the different substrates $(n$ = 3) for $48 \mathrm{~h}$. Total RNA was isolated using the RNAeasy isolation kit (Qiagen). cDNA was synthesized with $300 \mathrm{ng}$ RNA per sample using the Moloney murine leukemia virus (MMLV) reverse transcriptase enzyme/kit (Bio-Rad). cDNA samples were subjected to quantitative polymerase chain reaction using iQ SYBR Green Supermix (Bio-Rad) and the Bio-Rad IQ5 detection system (version 1.6). mRNA expression was normalized to glyceraldehyde 3-phosphate dehydrogenase as the reference gene and expressed as fold increase with respect to the control group. Primer sequences can be found in the Supporting Information.

2.4.5. Immunofluorescent Staining. $\alpha$-Smooth muscle actin expression was detected in differentiated HCASMC that were cultured on the different substrates $(n \geq 3)$ for 7 days. Cells were first washed with PBS, fixated in $3.7 \%$ formaldehyde (Merck) for $10 \mathrm{~min}$, washed with PBS, and permeabilized with $0.5 \%$ Triton X-100 (Merck) for $15 \mathrm{~min}$. Nonspecific binding of antibodies was minimized by incubating twice in $1 \%$ horse serum (Gibco) for $30 \mathrm{~min}$. Cells were then incubated with the primary antibody (mouse monoclonal anti-smooth muscle actin) (Dako, M0851) in 4\% horse serum in PBS + 1\% Tween at room temperature for 90 min. Subsequently, cells were washed with PBS $+1 \%$ Tween and incubated with the secondary antibody (Alexa Fluor 555conjugated goat anti-mouse antibody) (Life Technologies, A21422) in the dark for $45 \mathrm{~min}$, followed by incubation with 4',6-diamidino-2-phenylindole (DAPI) $(0.1 \mu \mathrm{g} / \mathrm{mL})$ in PBS for $5 \mathrm{~min}$. Finally, samples were washed and mounted on cover glasses with Mowiol (Sigma). Samples were imaged with a Zeiss Axiovert 200M epifluorescence microscope.

2.5. Statistical Analyses. Data are presented as average \pm standard deviation. Statistically significant differences were determined using a nonparametric Kruskal-Wallis test followed by Dunn's posthoc test. Asterisks in the figures indicate significant differences $(* p<0.05)$. All statistical analyses were performed using GraphPad Prism 5 software (GraphPad Software, Inc.).

\section{RESULTS \& DISCUSSION}

3.1. Peptide Synthesis and UPy Functionalization. Synthesis of the Jagged1-mimicking peptide $\left(\mathrm{DSL}_{\mathrm{JAG}}\right)$ was achieved using standard Fmoc-chemistry on a solid support. Conjugation of the UPy moiety to peptide's N-terminus on the solid support was performed using a UPy-carboxylic acid 
synthon activated with HATU in the presence of DIPEA to obtain the compound UPy-DSL $\mathrm{JAG}$ (Scheme S1). Compounds $\operatorname{DSL}_{\text {JAG1 }}$ (31 mg, 31\% yield) and UPy-DSL JAG1 $(23 \mathrm{mg}, 35 \%$ yield) were obtained as white powders after prep-RP-HPLC purification. Detailed results of RP-HPLC-MS analyses are available in the Supporting Information (Figure S1).

3.2. Characterization of Functionalized UPy-PCL Surfaces. UPy-PCL films, pristine or with addition of 1 and $5 \mathrm{~mol} \% \mathrm{UPy}_{\mathrm{DSL}} \mathrm{DAG}_{\mathrm{J} 1}$, were cast from solution and studied by tapping-mode AFM, XPS, and WCA to investigate the topography and confirm exposure of the peptide on the surface. Phase-mode AFM micrographs of pristine UPy-PCL confirm the presence of a nanofiber network, with the appearance of phase-separated domains when UPy-DSL $\mathrm{JAG}_{\mathrm{JA}}$ is added (Figure 2A). Images recorded in the height mode are available in the Supporting Information (Figure S2). We propose that the domains visible on the AFM micrographs of UPy-PCL + 1-5 mol \% UPy-DSL JAG1 $_{\text {correspond to an }}$ enhanced exposure of the UPy-peptide at the surface. XPS measurements show that the intensity of the characteristic nitrogen peak increases and the characteristic sulfur peak appears when the peptide is introduced (Figure 2B,C). Elemental analysis indicated that the relative abundance of nitrogen and sulfur increased from 4.9 to $0.0 \%$, respectively, in the pristine material to 8.3 and $0.7 \%$, respectively, with the addition of $1 \mathrm{~mol} \% \mathrm{UPy}-\mathrm{DSL}_{\mathrm{JAG}}$. With the addition of $5 \mathrm{~mol}$ $\%$ of UPy-DSL $L_{\text {JAG1 }}$, these values changed to 9.9 and $1.0 \%$ (Table 1). From the results of elemental analysis, it can be

Table 1. Relative Atomic Abundance of UPy-PCL Surfaces Functionalized with UPy-DSL JAG1 $_{\text {I }}$

\begin{tabular}{|c|c|c|c|c|}
\hline surface & $\begin{array}{c}\text { carbon } \\
{[\%]}\end{array}$ & $\begin{array}{c}\text { oxygen } \\
{[\%]}\end{array}$ & $\begin{array}{c}\text { nitrogen } \\
{[\%]}\end{array}$ & $\begin{array}{c}\text { sulfur } \\
{[\%]}\end{array}$ \\
\hline UPy-PCL & 75.0 & 20.1 & 4.9 & 0.0 \\
\hline$+1 \mathrm{~mol} \% \mathrm{UPy}^{-\mathrm{DSL}_{\mathrm{JAG}}}$ & 71.7 & 19.3 & 8.3 & 0.7 \\
\hline$+5 \mathrm{~mol} \% \mathrm{UPy}^{-\mathrm{DSL}_{\mathrm{JAG}}}$ & 70.5 & 18.6 & 9.9 & 1.0 \\
\hline
\end{tabular}

deducted that increasing the concentration of the additive in the supramolecular mix above $5 \mathrm{~mol} \%$ might not lead to significant increase in the surface presentation of UPy-DSL $\mathrm{JAG}_{\mathrm{JA}}$. Surface abundance of nitrogen and sulfur seems to not scale linearly with the concentration but rather reached toward a plateau at $5 \mathrm{~mol} \%$. Indeed, UPy-PCL films containing up to 10 and $25 \mathrm{~mol} \% \mathrm{UPy}_{\mathrm{DSL}} \mathrm{JAG1}_{\mathrm{J}}$ appeared fragile and lost partly their integrity (data not shown), suggesting that such composition would not prove suitable for applications that require a solid material. AFM micrographs confirm that the system appears to reach surface saturation around a mixing concentration of UPy-DSL $\mathrm{JAG}_{1}$ of $5 \mathrm{~mol} \%$ as the surface is almost fully covered with phase-separated domains.

It is relevant for biomaterials to investigate whether the modification affects their hydrophilicity. The measured WCA of pristine UPy-PCL is $72^{\circ} \pm 1^{\circ}$, and it slightly decreases to $68^{\circ} \pm 1^{\circ}$ and $67^{\circ} \pm 1^{\circ}$ when UPy-DSL $\mathrm{JAG}_{\mathrm{J} 1}$ is mixed with UPyPCL in concentrations of 1 and $5 \mathrm{~mol} \%$, respectively. The WCA values are in line with previously reported WCAs of UPy-PCL systems with the addition of UPy-functionalized additives $^{34}$ and are likely to not influence cell adhesion and behavior on the polymer films.

3.3. Activity of UPy-DSL $\mathrm{JAG}_{1}$ Peptide Immobilized on a Solid Biomaterial Surface. In view of the bioactivity tests on a supramolecular material substrate, the response of the
HEK293 FLN1 cell line to the immobilized full-length Jagged1 ligand was screened. Notch-signaling activity increased dosedependently when increasing the concentration of the coating solution used to immobilize the full-length extracellular domain of the Jagged1 ligand (Figure S3). Culturing HEK293 FLN1 cells on immobilized FcJagged1 resulted in a significant increase in reporter activity, and the addition of DAPT, a $\gamma$-secretase inhibitor, lowered CSL reporter activity toward Fc-control levels (Figure 3). Activation of the Notch

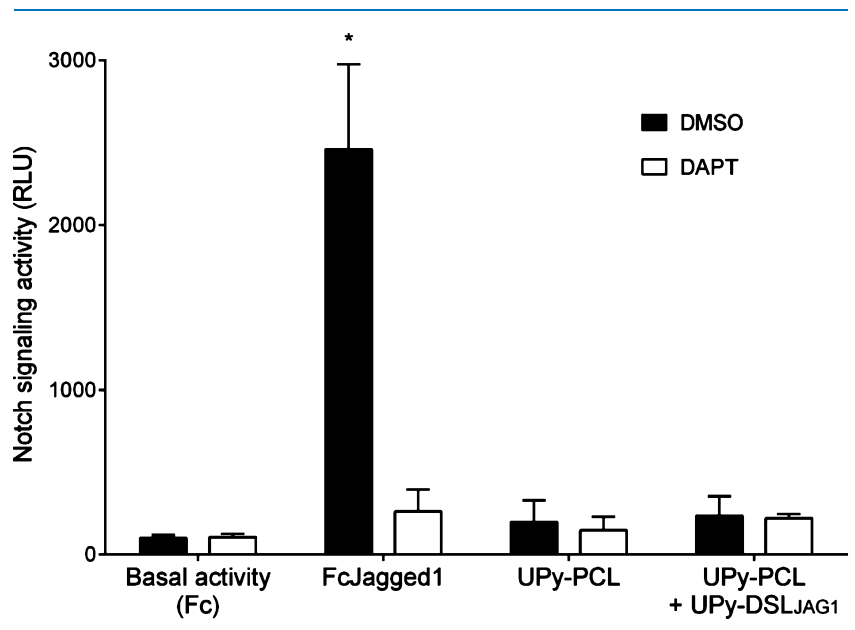

Figure 3. Effect of immobilized $5 \mathrm{~mol} \% \mathrm{UPy}_{\mathrm{DSL}} \mathrm{DAG}_{\mathrm{JA} 1}$ on the activation of $12 \times$ CSL-Luc in HEK293 FLN1, compared with the FcJagged1 ligand as the positive control. Data are normalized with respect to the negative control ( $\mathrm{Fc}$-fragment coating only).

pathway was tested on polymer films containing 5 mol \% UPy$\mathrm{DSL}_{\mathrm{JAG} 1}$ because the material characterizations revealed that the amount of additive present at the surface is directly proportional to its concentration in the drop-casting solution. Conversely to FcJagged 1 on plastic, no difference in Notchsignaling activity was detected on the drop-cast polymer functionalized with $5 \mathrm{~mol} \% \mathrm{UPy}_{\mathrm{DSL}} \mathrm{DAG1}_{\mathrm{J} 1}$ in comparison with pristine UPy-PCL. Consistently, the DAPT has no inhibitory effect on the observed signal intensity (Figure 3 ).

The effect of surface functionalization of UPy-PCL was investigated in a coronary artery smooth muscle cell (CASMC) model expressing the Notch3 receptor. Exposure of CASMC to FcJagged1-coated substrates induced upregulation of Notch target genes related to the regulation of transcription (HES1, HEY1) and to a positive feedback regulation of ligand and receptor production (JAG1, NOTCH3) (Figure 4A,C). A phenotypic switch of CASMC to $\alpha$-SMA expressing differentiated cells was observed as well on substrates coated with FcJagged1, on which expression of $\alpha$-SMA was confirmed both on the mRNA level (ACTA2) and protein level by immunostaining (Figure 4E,G-top row). On substrates containing immobilized UPy-DSL $\mathrm{JAG}_{\mathrm{J} 1}$, however, no upregulation of any of the mentioned genes was detected (Figure $4 \mathrm{~B}, \mathrm{D}$ ), as well as no expression of $\alpha$-SMA (Figure 4F,Gbottom row). Taken together, the data confirm that cell models expressing Notch1 and Notch3 receptors are responsive to surface-immobilized FcJagged1 but not to supramolecularly immobilized Jagged1-mimicking peptide, UPy-DSL JAG1 $_{\text {. }}$

One of the possible explanations of inactivity of the immobilized peptide could be a lack of strong anchoring of the peptide to the material, as the proposed mechanism of 

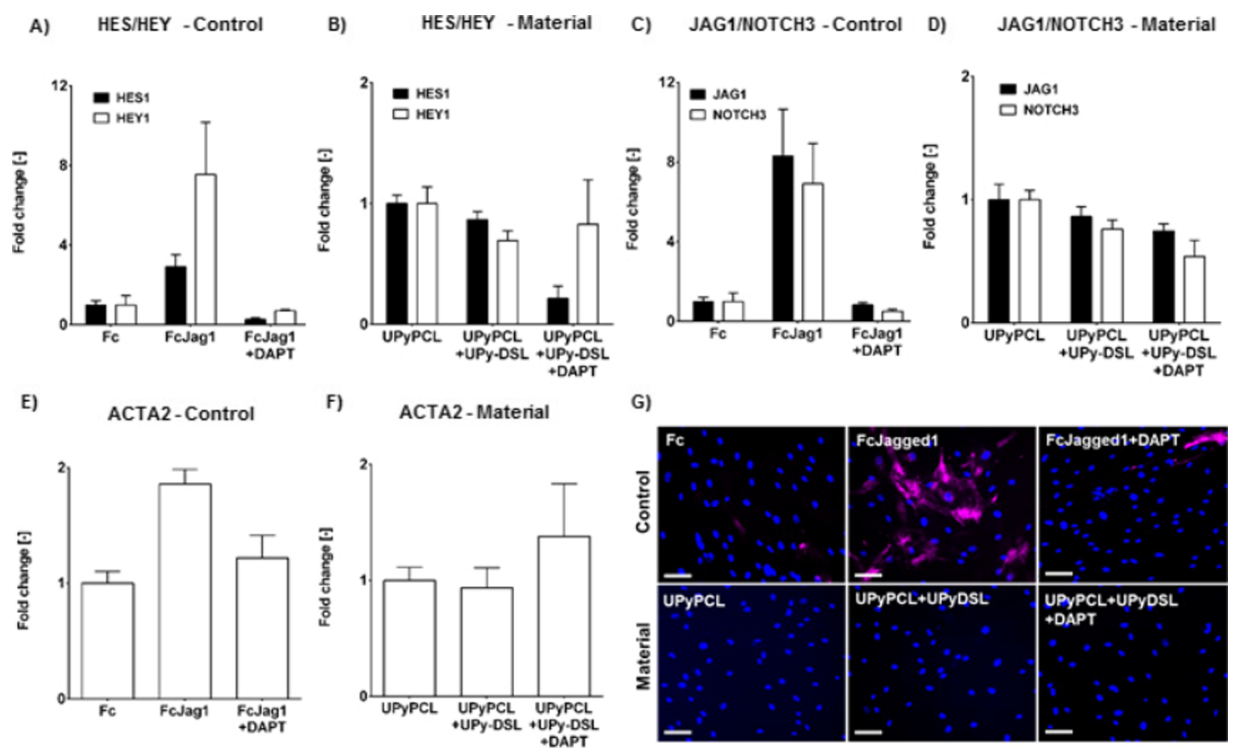

Figure 4. Effect of Notch ligand-functionalized substrates on HCASMCs. Gene expression of downstream Notch target genes HES1 and HEY1 on (A) control and (B) polymer surfaces. Expression of JAG1 and NOTCH3 genes related to lateral induction on (C) control and (D) polymer surfaces. Phenotypic switch of CASMC with expression of ACTA2 on the mRNA level on (E) control and (F) polymer surfaces. (G) CASMC differentiation to contractile phenotype visualized by immunofluorescence by DAPI (blue) and $\alpha$-SMA (magenta) staining (scale bar is $100 \mu \mathrm{m}$ ).
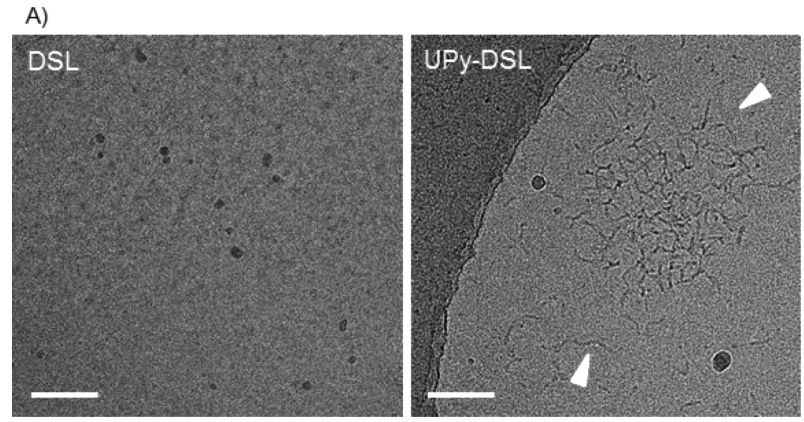

B)

... DSL JAG1

- UPY-DSLJAG

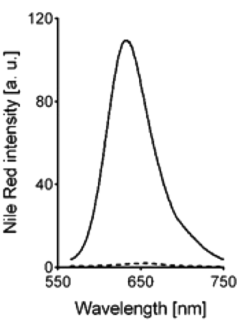

Figure 5. (A) Cryo-TEM micrographs of aqueous solutions of $\mathrm{DSL}_{\mathrm{JAG} 1}$ (left) and UPy-DSL $\mathrm{JAG}_{\mathrm{JG}}$ (right), with white arrowheads indicating fibrous assemblies (scale bar is $50 \mathrm{~nm}$ ). (B) Nile Red intensity of $50 \mu \mathrm{M}$ solutions of DSL $\mathrm{JAG}_{\mathrm{A} 1}$ (dotted line) and UPy-DSL $\mathrm{JAG1}_{\text {(s) }}$ (solid line).

Jagged1-mediated Notch-signaling activation involves a traction force exerted by the membrane-bound ligand on the receptor. Wang and $\mathrm{Ha}^{35}$ calculated experimentally the tension necessary to activate both integrin receptor and Notch1 receptors by immobilizing to a tension gauge tether RGDfK and Dll1 ligands, respectively. They found out that less than 12 $\mathrm{pN}$ was necessary to activate Notch signaling in CHO-1 cells, while a higher tension of approximately $40 \mathrm{pN}$ was required to trigger cell adhesion and spreading. Based on these data, we speculate that it is unlikely that inactivity of UPy-DSL $L_{\text {JAG1 }}$ immobilization is due to an insufficient pulling force generated on UPy-PCL, availing ourselves with existing evidence of cells responding to supramolecularly immobilized UPy-RGD with improved adhesion and morphology. ${ }^{26}$

After ligand-receptor engagement, intercellular phenomena of ligand internalization and contribution of modulators occur on both the signal-sending and signal-receiving cell sides, ${ }^{36-38}$ and glycosylation of Notch receptor's epidermal growth factorlike repeats is believed to be crucial as well. ${ }^{39,40}$ This complex mechanism might be insufficiently reproduced on our fully synthetic supramolecular material. Furthermore, short ligand

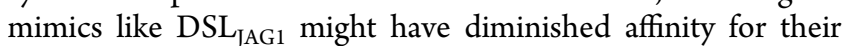
target receptor, and the surface analyses in Figure 2 suggest that the ligand concentration on a surface is limited. As a consequence, the affinity of the surface-bound Jagged1mimicking peptide for Notch receptors might not be sufficient to activate Notch signaling. In light of this, we hypothesize that the results reported are consequences of ineffective ligand presentation on the surface.

3.4. Characterization of the UPy-DSL $\mathrm{JAG}_{\mathrm{J} 1}$ Assembly in Solution. UPy-DSL $\mathrm{JAG}_{1}$ is equipped with two alkyl chains (C6 and $\mathrm{C} 12$, respectively) intercalated by a hydrogen bonding urea unit that ensure the formation of stable stacks in polar media. Furthermore, UPy-DSL JAG1 $_{1}$ contains by design a hydrophilic oligo(ethylene glycol) spacer with 12 ethylene glycol repeating units, which provide additional stability to the assembled aggregates in solution. Additionally, we know from previous studies that UPy compounds with this design assemble in an aqueous environment into fibrous aggregates. $^{21,22}$ Therefore, aqueous solutions of $\mathrm{DSL}_{\mathrm{JAG} 1}$ and UPyDSL $_{\text {JAG1 }}$ were analyzed by cryo-TEM. Cryo-TEM micrographs of unconjugated $\mathrm{DSL}_{\mathrm{JAG} 1}$ show no signs of clusters (Figure $5 \mathrm{~A}$, left; Figure S4A). On the contrary, UPy-DSL $\mathrm{JAG}_{\mathrm{JG}}$ appears to form a number of worm-like aggregates (Figure 5A right, Figure S4B). In order to further prove the self-assembly of UPy-DSL $L_{\mathrm{JAG} 1}$ into fibrous stacks, solutions of $\mathrm{DSL}_{\mathrm{JAG} 1}$ and $\mathrm{UPY}_{\mathrm{DSL}} \mathrm{JAG1}_{\mathrm{A} 1}$ at $50 \mu \mathrm{M}$ were incubated with Nile Red and excited at $550 \mathrm{~nm}$. Only the solution of UPy-DSL $\mathrm{JAG}_{\mathrm{JA}}$, but not 


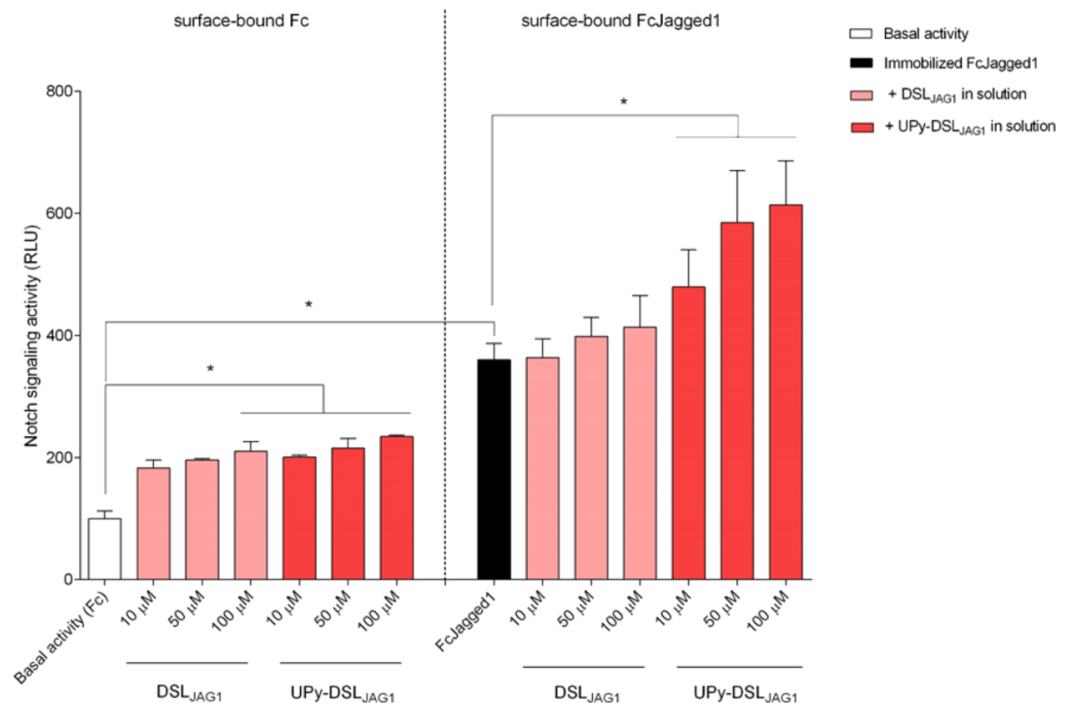

Figure 6. Effect of soluble DSL $\mathrm{JAG}_{\mathrm{J} 1}$ (pink bars) and UPy-DSL $\mathrm{JAG}_{\mathrm{J} 1}$ (red bars) on Notch-signaling activity in the HEK293 FLN1 cell line cultured on Fc coating (basal activity-white bar) or FcJagged1 coating (enhanced basal activity-black bar). Soluble molecules are used at concentrations of 10, 50, and $100 \mu \mathrm{M}$. Data are normalized with respect to the Fc control.

the nonfunctionalized $\mathrm{DSL}_{\mathrm{JAG} 1}$, resulted in a strong fluorescent emission with a maximum at $634 \mathrm{~nm}$ (Figure 5B), which corresponds to the emission of Nile Red in a lipophilic environment. $^{41}$

3.5. Activity of UPy-DSL $\mathrm{JAG}_{\mathrm{A} 1}$ Nanoaggregates in Solution. Nanoaggregates of UPy-DSL $\mathrm{JAG1}_{1}$ were administered in solution to HEK293 FLN1 cells stimulated with immobilized full-length FcJagged1 (or only Fc fragment as the control). This experimental setup allows decoupling of the effects of the distribution of UPy-DSL $\mathrm{JAG}_{\mathrm{JG}}$ in the UPy-PCL matrix from the effect of UPy functionalization of the Jagged1mimicking peptide sequence.

Exposure of the HEK293 FLN1 cell line to soluble DSL $\mathrm{JAG}_{1}$

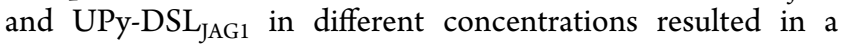
significant two-fold increase in the $12 \times$ CSL-Luc activity on the control Fc-coated substrate (Figure 6). The observed increase in Notch activity was lowered back to control levels by addition of the $\gamma$-secretase inhibitor DAPT (Figure S5). These evidences are in agreement with literature, as several authors reported the use of the soluble Jagged1-mimicking peptide in order to activate Notch signaling in different cell models or tissues. These reports show either direct evidence of Notch activation, such as Notch intracellular domain cleavage ${ }^{42}$ and regulation of transcription ${ }^{43}$ or further downstream Notch function-related events, such as contractile differentiation of arterial smooth muscle cells. ${ }^{44}$ In the proposed model of canonical Notch-signaling activation, the anchoring of the ligand or ligand-mimic to the material surface seems to be an absolutely necessary condition. Nevertheless, it is apparently possible that in certain cell models, the presentation of ligands, receptors, or modulators occurs in concentrations or configurations that allow transcending of the classical conditions required to initiate the Notch activation cascade. A recent study from Luca et al. supports this statement, as it reports on a high-affinity version of the Jagged1 ligand, which requires threshold activation forces that are lower than the wild-type ligand. ${ }^{45}$ Importantly, the capability of UPy-DSL ${ }_{\text {JAG1 }}$ of activating Notch signaling in the soluble form, equally to DSL $_{\text {JAG1 }}$, confirms that UPy functionalization does not affect its functionality in terms of Notch receptor engagement.
The effect of soluble $\mathrm{DSL}_{\mathrm{JAG} 1}$ or UPy-DSL $\mathrm{JAG}_{\mathrm{JA}}$ is milder than the effect of immobilized full-length FcJagged1, which causes a 3.6-fold increase in the $12 \times$ CSL-Luc activity. On FcJagged1coated surfaces, the addition of soluble UPy-DSL JAG1 at different concentrations in the culture medium resulted in a significant 1.6-fold increase in Notch-signaling activity with respect to the FcJagged 1 stimulation alone, while there was no effect of nonfunctionalized $\mathrm{DSL}_{\mathrm{JAG} 1}$. Clustering of ligands and receptor has been proposed to direct Notch signaling as well. ${ }^{46-48}$ Morrison et al. reported that a soluble FcDll1 dimer was not able to activate Notch signaling, but a multimer preclustered via antibodies could at least lead to ligand binding. ${ }^{49}$ Along the same lines, Narui and Salaita employed lipid membranes with tunable dynamics to control the lateral mobility of FcDll4 ligands and found out that the conditions in which ligand's mobility was constrained resulted in activation of Notch receptors. ${ }^{50}$ Similarly, the concentration of the $\mathrm{DSL}_{\mathrm{JAG} 1}$ peptide into supramolecular stacks recalls a clustering behavior that might be sufficient to increase the affinity of UPy-DSL $L_{\text {JAG1 }}$ for the Notch receptors of HEK293 FLN1 cells. However, clustering of Jagged1-mimicking peptides does not explain the increase in Notch-signaling activity observed equally with both $\mathrm{DSL}_{\mathrm{JAG} 1}$ and UPy-DSL $\mathrm{JAG1}_{1}$ on Fc-coated substrates. It is proposed that two different mechanisms of Notch activation might be involved on the different substrates, leading to the different magnitudes of the response of HEK293 FLN1 to soluble (UPy-)DSL $\mathrm{JAG}_{\mathrm{J} 1}$ on Fc or FcJagged1 coatings. The stimulation by immobilized FcJagged 1 leads to a series of feedback events at the level of the ligand and receptor, for example, causing clustering of the receptors themselves, ${ }^{51}$ which might lead to a propensity of receptors to stimuli from UPy-DSL $L_{\mathrm{JAG} 1}$. On the other hand, on Fc-coated plates, the binding of (UPy-)DSL $\mathrm{JAG1}_{\mathrm{JA}}$ might occur on unstimulated receptors that do not differentiate between clustering, or lack of, between $\mathrm{DSL}_{\mathrm{JAG} 1}$ molecules.

Although the UPy-modified Jagged1-mimiciking peptide was found to preserve a certain amount of activity in the soluble form, this is not immediately applicable in tissue engineering that requires solid materials. The findings in Figure 6 might be useful in applications that require, for example, release of 
bioactives. However, these results require further investigation to precisely ascertain the dependence of the phenomena on the cell type and context. During our study, we incurred into a variability of cell response to soluble additives, with different cell populations of the same cell line responding to both immobilized FcJagged 1 and soluble (UPy-)DSL JAG1 $_{1}$ with very different intensities of Notch-signaling activity (Figures S6 and S7).

Based on these results, the creation of a bioactive material suitable for cardiovascular tissue engineering that activates Notch signaling via a short Jagged1-mimicking peptide could better occur through the design of multivalent peptide-bearing additives or by means of a system that allows coupling of the full-length FcJagged1 extracellular domain to the material surface.

\section{CONCLUSIONS}

Conjugation of a UPy unit to a Jagged1-mimicking peptide allowed for the assembly of the UPy-DSL $\mathrm{JAG}_{\mathrm{J} 1}$ compound as an additive into a supramolecular material in the solid state and as an aggregate in aqueous solution via dynamic noncovalent interactions. Surface analyses confirmed that direct mixing of $\mathrm{UPy}_{\mathrm{DSL}} \mathrm{JAG1}_{\mathrm{J}}$ into solid UPy-PCL resulted in its surface exposure after film casting. In vitro studies on cell models expressing Notch1 and Notch3 receptors revealed that UPy$\mathrm{DSL}_{\mathrm{JAG} 1}$ is not efficient as a solid additive in achieving activation of the Notch/CSL pathway. The truncated $\mathrm{DSL}_{\mathrm{JAG} 1}$ peptide appears to have preserved Notch-activating properties on our Notch1 receptor expressing cell model in the soluble form. Furthermore, the conjugation of a UPy moiety to the Jagged1-mimicking peptide sequence seems to increase its ability to target the Notch receptor in the assembled state.

\section{ASSOCIATED CONTENT}

\section{S Supporting Information}

The Supporting Information is available free of charge on the ACS Publications website at DOI: 10.1021/acsomega.9b00869.

Scheme of the synthetic route and RP-HPLC-MS characterization of $\mathrm{DSL}_{\mathrm{JAG} 1}$ and UPy-DSL $\mathrm{JAG}_{1}$, AFM height micrographs of drop-cast films, dose-response behavior of HEK293 FLN1 on immobilized FcJagged1, additional cryo-TEM images, additional general materials, instrumentations and synthetic procedures, primer sequences, and dose-response behavior of HEK293 FLN1 to soluble DSL and UPy-DSL peptides (PDF)

\section{AUTHOR INFORMATION}

\section{Corresponding Author}

*E-mail: p.y.w.dankers@tue.nl. Phone: +31 402475451.

\section{ORCID}

Patricia Y. W. Dankers: 0000-0002-8997-181X

\section{Notes}

The authors declare no competing financial interest.

\section{ACKNOWLEDGMENTS}

Carlijn Bouten is acknowledged for valuable discussions, PeterPaul Fransen for providing the UPy-COOH synthon, Tiny Verhoeven for assistance with XPS measurements, and Jiankang Song for help with the Nile Red assay. The ICMS Animation Studio is acknowledged for creating the cartoons.
This work was funded by the European Research Council (FP7/2007-2013) grant agreement 604514 and ERC grant agreement 308045 and the Ministry of Education, Culture and Science (Gravity Program 024.001.03).

\section{REFERENCES}

(1) Artavanis-Tsakonas, S.; Rand, M. D.; Lake, R. J. Notch Signaling: Cell Fate Control and Signal Integration in Development. Science 1999, 284, 770-776.

(2) Hansson, E. M.; Lendahl, U.; Chapman, G. Notch Signaling in Development and Disease. Semin. Canc. Biol. 2004, 14, 320-328.

(3) Varnum-Finney, B.; Xu, L.; Brashem-Stein, C.; Nourigat, C.; Flowers, D.; Bakkour, S.; Pear, W. S.; Bernstein, I. D. Pluripotent, Cytokine-Dependent, Hematopoietic Stem Cells Are Immortalized by Constitutive Notch1 Signaling. Nat. Med. 2000, 6, 1278-1281.

(4) Wang, W.; Yu, S.; Zimmerman, G.; Wang, Y.; Myers, J.; Yu, V. W. C.; Huang, D.; Huang, X.; Shim, J.; Huang, Y.; et al. Notch Receptor-Ligand Engagement Maintains Hematopoietic Stem Cell Quiescence and Niche Retention. Stem Cells 2015, 33, 2280-2293.

(5) Baghdadi, M. B.; Castel, D.; Machado, L.; Fukada, S.-I.; Birk, D. E.; Relaix, F.; Tajbakhsh, S.; Mourikis, P. Reciprocal signalling by Notch-Collagen V-CALCR retains muscle stem cells in their niche. Nature 2018, 557, 714-718.

(6) Karanu, F. N.; Murdoch, B.; Gallacher, L.; Wu, D. M.; Sakano, S.; Bhatia, M. The Notch Ligand Jagged-1 Represents a Novel Growth Factor of Human Hematopoietic Stem Cells. J. Exp. Med. 2000, 192, 1365-1372.

(7) Poulos, M. G.; Guo, P.; Kofler, N. M.; Pinho, S.; Gutkin, M. C.; Tikhonova, A.; Aifantis, I.; Frenette, P. S.; Kitajewski, J.; Rafii, S.; et al. Endothelial Jagged-1 Is Necessary for Homeostatic and Regenerative Hematopoiesis. Cell Rep. 2013, 4, 1022-1034.

(8) Liu, C. Y.; Westerlund, U.; Svensson, M.; Moe, M. C.; Varghese, M.; Berg-Johnsen, J.; Apuzzo, M. L. J.; Tirrell, D. A.; Langmoen, I. A. Artificial Niches for Human Adult Neural Stem Cells: Possibility for Autologous Transplantation Therapy. J. Hematother. Stem Cell Res. 2003, 12, 689-699.

(9) Pedrosa, A.-R.; Trindade, A.; Fernandes, A.-C.; Carvalho, C.; Gigante, J.; Tavares, A. T.; Diéguez-Hurtado, R.; Yagita, H.; Adams, R. H.; Duarte, A. Endothelial Jagged1 Antagonizes Dll4 Regulation of Endothelial Branching and Promotes Vascular Maturation Downstream of Dll4/Notch1. Arterioscler. Thromb. Vasc. Biol. 2015, 35, $1134-1146$

(10) Kusumbe, A. P.; Ramasamy, S. K.; Itkin, T.; Mäe, M. A.; Langen, U. H.; Betsholtz, C.; Lapidot, T.; Adams, R. H. AgeDependent Modulation of Vascular Niches for Haematopoietic Stem Cells. Nature 2016, 532, 380-384.

(11) Li, L.; Milner, L. A.; Deng, Y.; Iwata, M.; Banta, A.; Graf, L.; Marcovina, S.; Friedman, C.; Trask, B. J.; Hood, L.; et al. The Human Homolog of Rat Jagged1Expressed by Marrow Stroma Inhibits Differentiation of 32D Cells through Interaction with Notch1. Immunity 1998, 8, 43-55.

(12) Nickoloff, B. J.; Qin, J.-Z.; Chaturvedi, V.; Denning, M. F.; Bonish, B.; Miele, L. Jagged-1 mediated activation of notch signaling induces complete maturation of human keratinocytes through NF- $\kappa \mathrm{B}$ and PPAR $\gamma$. Cell Death Differ. 2002, 9, 842-855.

(13) Cao, L.; Bouhadir, K. H.; Mooney, D. J. Materials Presenting Notch Signaling Molecules to Control Cell Behavior. U.S. Patent 0,331,343, 2013.

(14) Boopathy, A. V.; Che, P. L.; Somasuntharam, I.; Fiore, V. F.; Cabigas, E. B.; Ban, K.; Brown, M. E.; Narui, Y.; Barker, T. H.; Yoon, Y.-S.; et al. The Modulation of Cardiac Progenitor Cell Function by Hydrogel-Dependent Notch1 Activation. Biomaterials 2014, 35, $8103-8112$

(15) Boopathy, A. V.; Martinez, M. D.; Smith, A. W.; Brown, M. E.; García, A. J.; Davis, M. E. Intramyocardial Delivery of Notch LigandContaining Hydrogels Improves Cardiac Function and Angiogenesis Following Infarction. Tissue Eng., Part A 2015, 21, 2315-2322. 
(16) Beckstead, B. L.; Tung, J. C.; Liang, K. J.; Tavakkol, Z.; Usui, M. L.; Olerud, J. E.; Giachelli, C. M. Methods to Promote Notch Signaling at the Biomaterial Interface and Evaluation in a Rafted Organ Culture Model. J. Biomed. Mater. Res., Part A 2009, 91, 436446.

(17) Wen, F.; Wong, H. K.; Tay, C. Y.; Yu, H.; Li, H.; Yu, T.; Tijore, A.; Boey, F. Y. C.; Venkatraman, S. S.; Tan, L. P. Induction of Myogenic Differentiation of Human Mesenchymal Stem Cells Cultured on Notch Agonist (Jagged-1) Modified Biodegradable Scaffold Surface. ACS Appl. Mater. Interfaces 2014, 6, 1652-1661.

(18) Sijbesma, R. P.; Beijer, F. H.; Brunsveld, L.; Folmer, B. J. B.; Hirschberg, J. H. K. K.; Lange, R. F. M.; Lowe, J. K. L.; Meijer, E. W. Reversible Polymers Formed from Self-Complementary Monomers Using Quadruple Hydrogen Bonding. Science 1997, 278, 1601-1604.

(19) Folmer, B. J. B.; Sijbesma, R. P.; Versteegen, R. M.; Van Der Rijt, J. A. J.; Meijer, E. W. Supramolecular Polymer Materials: Chain Extension of Telechelic Polymers Using a Reactive HydrogenBonding Synthon. Adv. Mater. 2000, 12, 874-878.

(20) Dankers, P. Y. W.; Hermans, T. M.; Baughman, T. W.; Kamikawa, Y.; Kieltyka, R. E.; Bastings, M. M. C.; Janssen, H. M.; Sommerdijk, N. A. J. M.; Larsen, A.; Van Luyn, M. J. A.; et al. Hierarchical Formation of Supramolecular Transient Networks in Water: A Modular Injectable Delivery System. Adv. Mater. 2012, 24, 2703-2709.

(21) Bakker, M. H.; Kieltyka, R. E.; Albertazzi, L.; Dankers, P. Y. W. Modular Supramolecular Ureidopyrimidinone Polymer Carriers for Intracellular Delivery. RSC Adv. 2016, 6, 110600-110603.

(22) Hendrikse, S. I. S.; Wijnands, S. P. W.; Lafleur, R. P. M.; Pouderoijen, M. J.; Janssen, H. M.; Dankers, P. Y. W.; Meijer, E. W. Controlling and Tuning the Dynamic Nature of Supramolecular Polymers in Aqueous Solutions. Chem. Commun. 2017, 53, 22792282

(23) Bakker, M. H.; Tseng, C. C. S.; Keizer, H. M.; Seevinck, P. R.; Janssen, H. M.; Van Slochteren, F. J.; Chamuleau, S. A. J.; Dankers, P. Y. W. MRI Visualization of Injectable Ureidopyrimidinone Hydrogelators by Supramolecular Contrast Agent Labeling. Adv. Healthc. Mater. 2018, 7, 1701139.

(24) Hutin, M.; Burakowska-Meise, E.; Appel, W. P. J.; Dankers, P. Y. W.; Meijer, E. W. From Molecular Structure to Macromolecular Organization: Keys to Design Supramolecular Biomaterials. Macromolecules 2013, 46, 8528-8537.

(25) Wisse, E.; Spiering, A. J. H.; Dankers, P. Y. W.; Mezari, B.; Magusin, P. C. M. M.; Meijer, E. W. Multicomponent Supramolecular Thermoplastic Elastomer with Peptide-Modified Nanofibers. J. Polym. Sci., Part A: Polym. Chem. 2011, 49, 1764-1771.

(26) Dankers, P. Y. W.; Harmsen, M. C.; Brouwer, L. A.; van Luyn, M. J. A.; Meijer, E. W. A Modular and Supramolecular Approach to Bioactive Scaffolds for Tissue Engineering. Nat. Mater. 2005, 4, 568574.

(27) van Almen, G. C.; Talacua, H.; Ippel, B. D.; Mollet, B. B.; Ramaekers, M.; Simonet, M.; Smits, A. I. P. M.; Bouten, C. V. C.; Kluin, J.; Dankers, P. Y. W. Development of Non-Cell Adhesive Vascular Grafts Using Supramolecular Building Blocks. Macromol. Biosci. 2016, 16, 350-362.

(28) Bonito, V.; Smits, A. I. P. M.; Goor, O. J. G. M.; Ippel, B. D.; Driessen-Mol, A.; Münker, T. J. A. G.; Bosman, A. W.; Mes, T.; Dankers, P. Y. W.; Bouten, C. V. C. Modulation of Macrophage Phenotype and Protein Secretion via Heparin-IL-4 Functionalized Supramolecular Elastomers. Acta Biomater. 2018, 71, 247-260.

(29) Zaccaria, S.; van Gaal, R. C.; Riool, M.; Zaat, S. A. J.; Dankers, P. Y. W. Antimicrobial Peptide Modification of Biomaterials Using Supramolecular Additives. J. Polym. Sci., Part A: Polym. Chem. 2018, 56, 1926-1934.

(30) Muylaert, D. E. P.; van Almen, G. C.; Talacua, H.; Fledderus, J. O.; Kluin, J.; Hendrikse, S. I. S.; van Dongen, J. L. J.; Sijbesma, E.; Bosman, A. W.; Mes, T.; et al. Early in-situ cellularization of a supramolecular vascular graft is modified by synthetic stromal cellderived factor- $1 \alpha$ derived peptides. Biomaterials 2016, 76, 187-195.
(31) Mollet, B. B.; Comellas-Aragonès, M.; Spiering, A. J. H.; Söntjens, S. H. M.; Meijer, E. W.; Dankers, P. Y. W. A Modular Approach to Easily Processable Supramolecular Bilayered Scaffolds with Tailorable Properties. J. Mater. Chem. B 2014, 2, 2483.

(32) Sahlgren, C.; Gustafsson, M. V.; Jin, S.; Poellinger, L.; Lendahl, U. Notch Signaling Mediates Hypoxia-Induced Tumor Cell Migration and Invasion. Proc. Natl. Acad. Sci. U.S.A. 2008, 105, 6392-6397.

(33) Gustafsson, M. V.; Zheng, X.; Pereira, T.; Gradin, K.; Jin, S.; Lundkvist, J.; Ruas, J. L.; Poellinger, L.; Lendahl, U.; Bondesson, M. Hypoxia Requires Notch Signaling to Maintain the Undifferentiated Cell State. Dev. Cell 2005, 9, 617-628.

(34) Spaans, S.; Fransen, P. P. K. H.; Ippel, B. D.; de Bont, D. F. A.; Keizer, H. M.; Bax, N. A. M.; Bouten, C. V. C.; Dankers, P. Y. W. Supramolecular surface functionalization via catechols for the improvement of cell-material interactions. Biomater. Sci. 2017, 5, $1541-1548$.

(35) Wang, X.; Ha, T. Defining Single Molecular Forces Required to Activate Integrin and Notch Signaling. Science 2013, 340, 991-994.

(36) Meloty-Kapella, L.; Shergill, B.; Kuon, J.; Botvinick, E.; Weinmaster, G. Notch Ligand Endocytosis Generates Mechanical Pulling Force Dependent on Dynamin, Epsins, and Actin. Dev. Cell 2012, 22, 1299-1312.

(37) Yang, L.-T.; Nichols, J. T.; Yao, C.; Manilay, J. O.; Robey, E. A.; Weinmaster, G. Fringe glycosyltransferases differentially modulate Notch1 proteolysis induced by Deltal and Jagged1. Mol. Biol. Cell 2005, 16, 927-942.

(38) Chillakuri, C. R.; Sheppard, D.; Ilagan, M. X. G.; Holt, L. R.; Abbott, F.; Liang, S.; Kopan, R.; Handford, P. A.; Lea, S. M. Structural Analysis Uncovers Lipid-Binding Properties of Notch Ligands. Cell Rep. 2013, 5, 861-867.

(39) Haines, N.; Irvine, K. D. Glycosylation Regulates Notch Signalling. Nat. Rev. Mol. Cell Biol. 2003, 4, 786-797.

(40) Schneider, M.; Kumar, V.; Nordstrøm, L. U.; Feng, L.; Takeuchi, H.; Hao, H.; Luca, V. C.; Garcia, K. C.; Stanley, P.; Wu, P.; et al. Inhibition of Delta-Induced Notch Signaling Using Fucose Analogs. Nat. Chem. Biol. 2018, 14, 65-71.

(41) Greenspan, P.; Fowler, S. D. Spectrofluorometric Studies of the Lipid Probe, Nile Red. J. Lipid Res. 1985, 26, 781-789.

(42) Yamamura, H.; Yamamura, A.; Ko, E. A.; Pohl, N. M.; Smith, K. A.; Zeifman, A.; Powell, F. L.; Thistlethwaite, P. A.; Yuan, J. X.-J. Activation of Notch Signaling by Short-Term Treatment with Jagged1 Enhances Store-Operated Ca2+ Entry in Human Pulmonary Arterial Smooth Muscle Cells. Am. J. Physiol.: Cell Physiol. 2014, 306, C871-C878.

(43) Hellström, M.; Phng, L.-K.; Gerhardt, H. VEGF and Notch Signaling. Cell Adhes. Migr. 2007, 1, 133-136.

(44) Kerr, B. A.; West, X. Z.; Kim, Y.-W.; Zhao, Y.; Tischenko, M.; Cull, R. M.; Phares, T. W.; Peng, X.-D.; Bernier-Latmani, J.; Petrova, T. V.; et al. Stability and Function of Adult Vasculature Is Sustained by Akt/Jagged1 Signalling Axis in Endothelium. Nat. Commun. 2016, 7, 10960 .

(45) Luca, V. C.; Kim, B. C.; Ge, C.; Kakuda, S.; Wu, D.; RoeinPeikar, M.; Haltiwanger, R. S.; Zhu, C.; Ha, T.; Garcia, K. C. NotchJagged Complex Structure Implicates a Catch Bond in Tuning Ligand Sensitivity. Science 2017, 355, 1320-1324.

(46) Seo, D.; Southard, K. M.; Kim, J.-w.; Lee, H. J.; Farlow, J.; Lee, J.-u.; Litt, D. B.; Haas, T.; Alivisatos, A. P.; Cheon, J.; et al. A Mechanogenetic Toolkit for Interrogating Cell Signaling in Space and Time. Cell 2017, 169, 1357.

(47) Biktasova, A. K.; Dudimah, D. F.; Uzhachenko, R. V.; Park, K.; Akhter, A.; Arasada, R. R.; Evans, J. V.; Novitskiy, S. V.; Tchekneva, E. E.; Carbone, D. P.; et al. Multivalent Forms of the Notch Ligand DLL-1 Enhance Antitumor T-Cell Immunity in Lung Cancer and Improve Efficacy of EGFR-Targeted Therapy. Cancer Res. 2015, 75, $4728-4741$

(48) Driessen, R. C. H.; Stassen, O. M. J. A.; Sjöqvist, M.; Suarez Rodriguez, F.; Grolleman, J.; Bouten, C. V. C.; Sahlgren, C. M. Shear Stress Induces Expression, Intracellular Reorganization and Enhanced 
Notch Activation Potential of Jagged1. Integr. Biol. 2018, 10, 719726.

(49) Morrison, S. J.; Perez, S. E.; Qiao, Z.; Verdi, J. M.; Hicks, C.; Weinmaster, G.; Anderson, D. J. Transient Notch Activation Initiates an Irreversible Switch from Neurogenesis to Gliogenesis by Neural Crest Stem Cells. Cell 2000, 101, 499-510.

(50) Narui, Y.; Salaita, K. Membrane Tethered Delta Activates Notch and Reveals a Role for Spatio-Mechanical Regulation of the Signaling Pathway. Biophys. J. 2013, 105, 2655-2665.

(51) Bardot, B.; Mok, L.; Thayer, T.; Ahimou, F.; Wesley, C. The Notch Amino Terminus Regulates Protein Levels and Delta-Induced Clustering of Drosophila Notch Receptors. Exp. Cell Res. 2005, 304, 202-223. 